\title{
A Novel Approach to Implementation of Lighting Design Using Virtual Reality
}

\author{
Akshay Babu \\ Department of electrical and \\ electronics engineering \\ Sahrdaya College of Engineering and \\ Technology, Kodakara
}

Abhijith R Prasad

\author{
Assistant professor, Department of electrical and \\ electronics engineering \\ Sahrdaya College of Engineering and Technology, \\ Kodakara
}

Abhijith R Prasad

\begin{abstract}
Architectural lighting style may be field among design, interior style and electrical engineering that's involved with the look of light system as well as natural light-weight, electric-light bulb, or each to serve human wants . Lighting design using virtual reality is an innovative approach towards electrical system design. The lighting design process and the current problems associated with them are solved by integrating two different branches of engineering along with electrical engineering. The problems associated with current lighting design such as excess illumination, improper arrangement and non uniformity can lead to several problems. This includes energy loss, cost overruns and eye strain. Implementation of lighting design using virtual reality helps to overcome many of these problems. It enable the identification of problems in the early stage of design itself by creating a 3D model of the proposed building and transforming it to a real time visual experience with the help of virtual reality concept. Hence the proper lighting calculation along with this will improve overall lighting design in terms of energy savings, cost , and aesthetics.
\end{abstract}

Keywords:- 3D Modeling, Virtual Reality, Average Lumen Method.

\section{INTRODUCTION}

Lighting style is that the application of lighting- as well as daylight once it's specifically used as supply of lighting - to human areas. Like style engineering and various vogue professions, lighting depends on a mix of specific scientific principles, established standards and conventions and type of aesthetic cultural ,human factors applied in an exceedingly clever manner.

The primary goal of any building electrical style is to supply a secure, energy economical system that meets the client's wants and is in compliance with codes. In the past decades, world's energy consumption have increased rapidly due to the increase in population and comfort demand of people. In this decade, the increase in energy consumption and associated carbon dioxide emissions are

\author{
Aleena Joseph \\ Department of electrical and \\ electronics engineering \\ Sahrdaya College of Engineering and \\ Technology, Kodakara
}

Aswathy VS

Department of electrical and electronics engineering Sahrdaya College of Engineering and Technology, Kodakara 
ISSN No:-2456-2165

Opportunity for real time visualization reduces the communication barrier between the designer and client[3]. Apart from this it also give lot of choices to the client so that he can set the arrangements as per his desire. A brief description of the selected design details should be appear in the final stage of presentation. It can be inco-operated as a script in UNITY.

\section{METHODOLOGY}

The design of the lighting system is taken into account with the work for the same in calculation of the needed lights. Number of required luminaires calculated using average lumen method during the initial step of the design. Other factors such as glare, illumination required, color, light loss factor, coefficient of utilization are also considered. Coefficient of utilization is the luminaires candle power distribution, efficiency, room size ,shape and luminaires height as the luminous flux produced by the lamps won't fall fully into the room in reality. To obtain the maintained luminance level the light loss factor is taken into consideration. Then after deciding the required luminaires drawing of the selected area need to be done.

Several drawing softwares are available such as blender, sketchup,3Ds max. Among that software chosen here is $3 \mathrm{ds}$ max. The basic form of a CAD drawing knowledge is necessary for getting a reference layout of the selected area.The main focus is on the things that is to be drawn in a room such as if there are chairs, tables ,cabins or bed etc. The software gives us the front, side and top views of the area.

The next step is the integration into unity .Unity is a game engine which provide a real time pre visualization of area. The user interface can be fixed as per the designer idea. Separate programming scripts can be formed so that it makes easy for further editing and concept understanding. Lighting in unity can be set in two ways such as point lighting and spot lighting. It facilitate the option for varying the range and angle so that different lighting schemes can be observed easily. The final view can be seen with the help of a oculus rift head mount, VR headset which gives us a simulated environment.

So number of luminaires can be calculated as, RoomArea Lux

$N=$ $=7$ luminaires

\begin{tabular}{|c|c|c|}
\hline $\begin{array}{c}\text { SL } \\
\text { NO. }\end{array}$ & PARAMETERS & VALUE \\
\hline 1. & Reflectance code & 752 \\
\hline & & \\
\hline 2. & Utilization factor & 0.66 \\
\hline & & \\
\hline 3. & Maintenance factor & 0.8 \\
\hline 4. & Room index & 1.8 \\
\hline 5. & Number of luminaries & 7 \\
\hline
\end{tabular}

Table 1:- design parameters.

After performing the lighting calculations, the way by which the $3 \mathrm{~d}$ max as well as integrating it to unity has taken place can be seen here. The top view of the selected area with all the necessary items can be seen in fg1. This image is drawn in CAD to get the layout of the main picture. So the top view is shown in fig 1. After drawing in the $\mathrm{CAD}$,the same is done in $3 \mathrm{ds}$ max where the materials for the room is decided. So the image drawn in $3 \mathrm{ds}$ max can be seen in fig2

Room size and material in both the softwares should be checked and adjusted equally before entering into UNITY. By integrating it in unity, the lights as well as the user interface is decided and also the image after lighting in 3Ds max can be seen in fig 3 .

\section{IMPLEMENTATION}

The primary focus of concept implementation is the advancement of electrical system design. The design should have most economical, safe, reliable, energy efficient and sustainable method. While providing adequate illumination, the provision for light distribution all over the working plane must be uniform as possible.. Also there is a need for providing light of suitable colors and to avoid glare and hard shadows as far as possible.

The design of the room here includes finding the area of cross section of the room first. Selected area posses length $=6 \mathrm{~m}$, breadth $=9 \mathrm{~m}$ and height $=3 \mathrm{~m}$. After calculating the room index of the room, then the lumens required are calculated .The reflectance code for selected office area is found that is to be $70 \%$ in ceiling , $50 \%$ in wall and $20 \%$ for floor. So here the room index is taken as 1.8. Also there are other factors such as reflectance code taken as 752 and utilization factor as 0.66. Maintenance factor is taken as 0.8 as standard .If using Philips green perform LED batten of $20 \mathrm{KW}$ the lumen per watt will be $40001 \mathrm{~m} / 20 \mathrm{w}$ and the lamp color will be neutral white $4000 \mathrm{~K}$.The color rendering index is taken greater than 80 with lifetime 50,000 hours. 


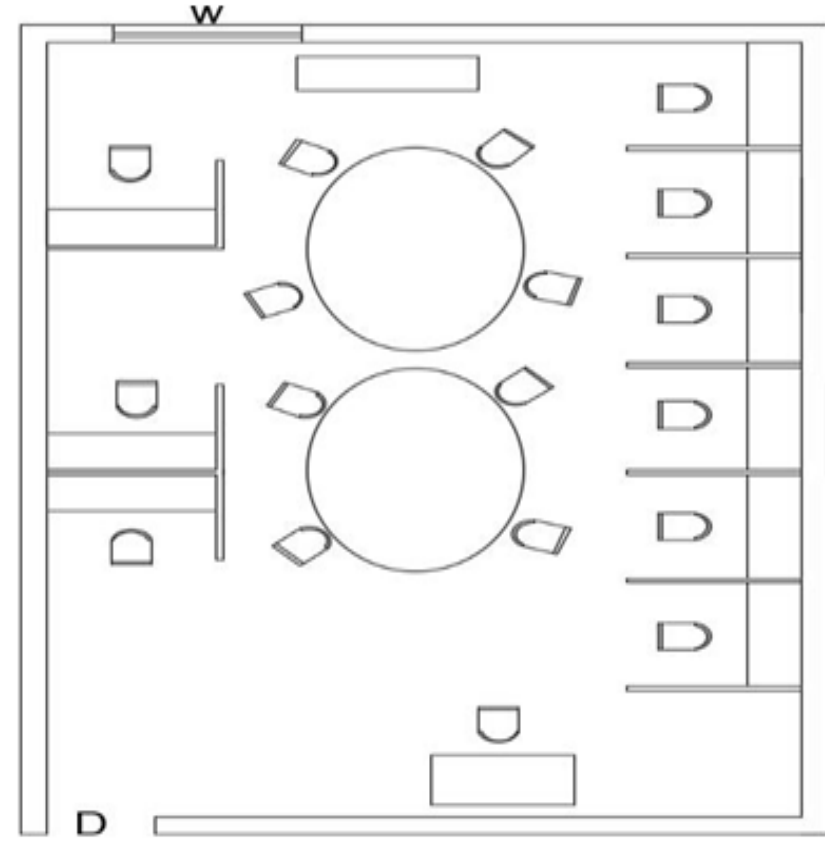

Fig 1:- CAD drawing of selected room

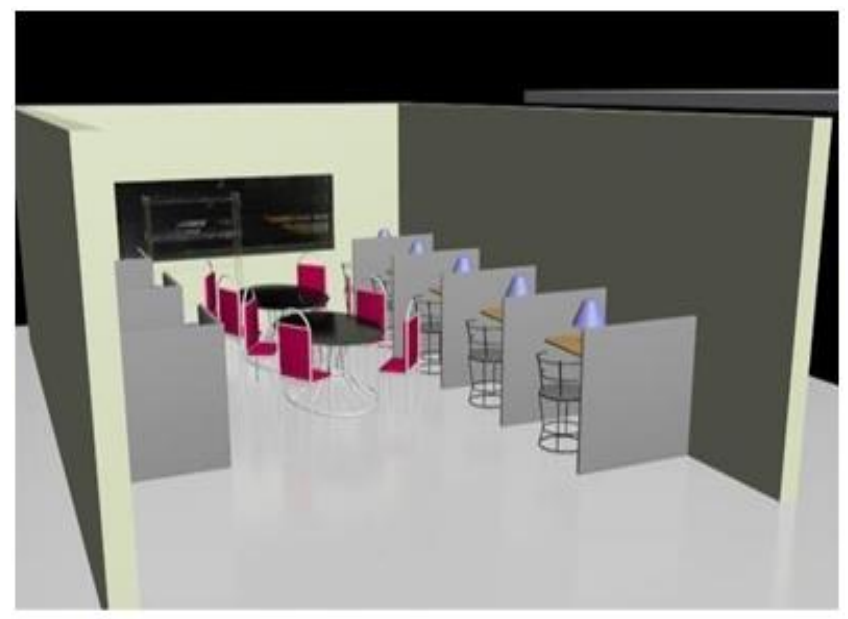

Fig 2:- Top view of 3D drawing of selected area

$\mathrm{CAD}$ (computer aided design) is a computer software to design and document products design process. It will ensure the efficiency in quality of system, increase engineers productivity and improve record keeping through better documentation and communication. As we require the referance plan here the length and the width of the room, number of cabins and spacing required in cabin etc are the information's required. Then the arrangement of the same is done with the different tools in drawing panel, modify panel and layer panel.

Now using the CAD model as the reference, we have a three dimensional modeling design and realistic animation. There is polygon modeling available which is mainly used in game engines. The primitive shapes options are available here which has the shapes such as teapots, pyramids etc which can be used for the base model development . The smoothening of surface or for doing some modifications in the surfaces an option subdivision is available in the software. Also for custom lighting and shadows. So by using these options the drawing of the room that we have selected is done. Then the different views after lighting and before lighting has been shown before. After the drawing the required lights for the same also been drawn in this software itself and imported to unity software. For importing this into unity there is a need to change the format .The ".max" format must be changed into ".fbx" .The format changing options are available in the $3 \mathrm{ds}$ max itself.

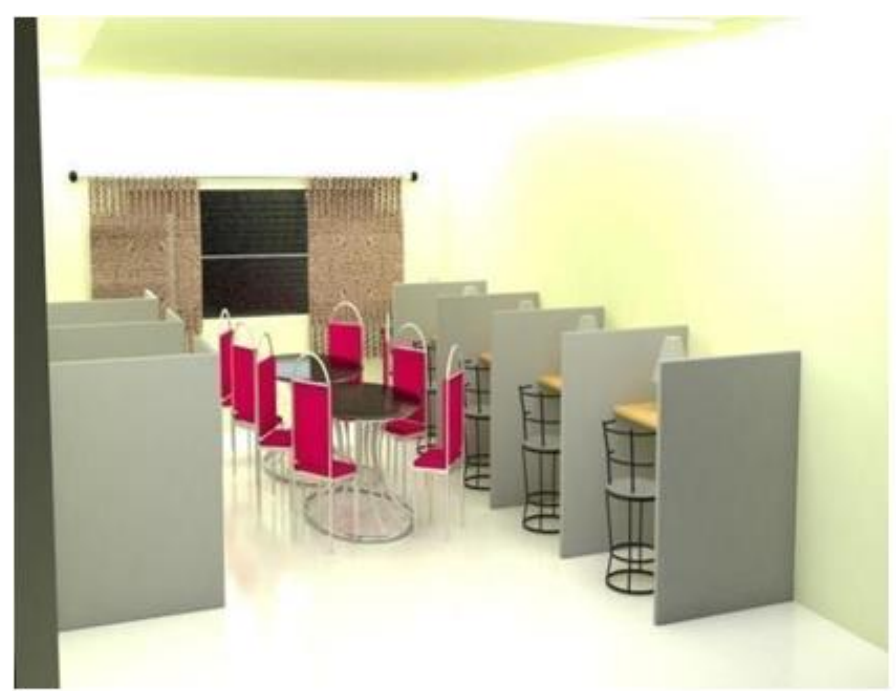

Fig 3:- Final rendered image of the selected area in 3Ds $\max$

Integrating it into unity we have two main constraints to look upon. firstly the user interface (UI) setting and then the lighting in unity. So for the UI setting the selection process for the same is done in "grt event system" .This is used because we are using the Google cardboard for our VR. The focusing ray or the point is setup using the option "main camera" under grt event system [6]. The reticle pointer is used to control the ray. This is mainly for creating the touch or experience as an activity which is called an event. Now using the initial screen icon we can select the required windows such as windows for lamp selection, watt selection etc.To determine which all things to be displayed on screen there is a selection called initialize UI state. So all the UI settings can be assigned as a script and the conditions for the same can be given as per our design requirements.

The lighting in unity can be given in two ways, that is spot lighting and point lighting. The range and angle of spot light can be varied as per designer choice. Table lamps and pendent lamps are provided with spot light. Whereas for ceiling light, it is given with point lighting. The spot light posses angle ,this is the main difference between the two. Integer values are given to represent intensity in terms of watts. All the options for this lighting is available in Art icon. There are two types of UI rendering called UI canvas and $2 \mathrm{~d}$ sprite render. There are also other two types of script such as the lamp variant script and watt variant script. In lamp variant script we can change the name, cost and other general details etc. We can only use a particular real 
time light intensity since unity is rendering in a android platform. This is due to the heavy performance need.

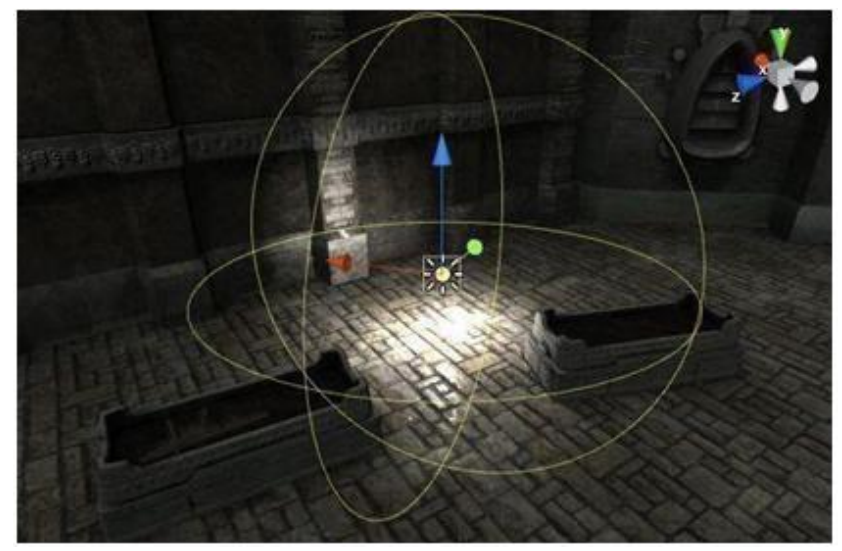

Fig 4:- workspace in unity.

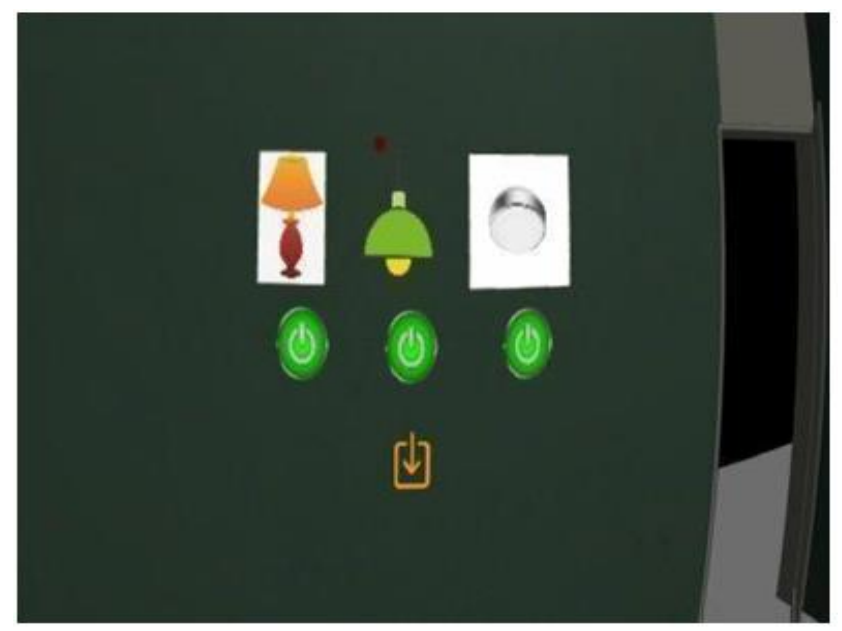

Fig 5:- User interface.

\section{SOFTWARE USED}

\section{$>C A D$}

CAD (Computer Aided Design) is a computer software which is used to design and document a product's design process. It is used to design and optimize products.

\section{$>3 D S M A X$}

3DS MAX software consists of 3D modeling design, realistic animation, and renders of 3D models. Autodesk $3 \mathrm{ds}$ Max is the software for rendering 3D animation, models and imagery. It is primarily, although not completely, based on polygon modeling, which is used more extensively in game design than in other animation application as it offers a highly specific dominance over individual polygons that make up the model. This feature also allow for greater optimization of the model.

\section{$>$ UNITY}

Unity3D may be a powerful cross platform 3D engine and a user friendly development setting. Straightforward enough for the beginner and powerful enough for the expert, unity ought to interest anybody .. Along with it they can also be used to make Virtual Reality and Augmented Reality games as well as experiences.

\section{HARDWARE REQUIREMENTS}

\section{$>V R$ HEADSET}

A virtual reality headset is a head-mounted device which provides virtual reality for the viewer. They are widely used with video games but also used in other applications such as simulators and trainers. The VRheadset consist of a stereoscopic head mounted show that's providing separate picture for every eye, stereo sound and head motion following sensors that could embrace gyroscopes, accelerometers , magnetometers, structured light-weight systems etc. Some also have eye tracking sensors and gaming controllers.

\section{$>$ ANDROID CELLPHONE}

In order to play some VR stuff (Games, Apps, etc) using Google Cardboard we need a smart phone with 4GB + Ram, 1080p to $2 \mathrm{~K}$ Screen resolution, $1.4 \mathrm{GHz}+\mathrm{CPU}$ speed, Gyroscope, At least 4.7 inch display. Gyroscope is an Advance version of Accelerometer which signals the software at what angle and how much tilted the user is holding the phone. It helps in processing 360 videos or Image.

A gyro uses vibrations as suggests that of understanding motility movement so transmit in sort of electrical signal. It's the sensing element gift during a Smartphone that calculates angular speed.

\section{LAPTOP}

Only the simplest VR-ready laptops area unit capable of handling computer game headsets.Compatibility of VR depends upon the specifications of CPU, GPU, RAM, Hard drive , and other core components. Specifications of the laptop are; Processor 1.8 Ghz Dual core Intel core i5 with a Memory of 8GB $1600 \mathrm{MHz}$ DDR3, Graphics : Intel HD Graphics 6000.

\section{CONCLUSION}

Lighting design is important to maintain the power consumption to minimum level and lighting to an appreciable value. In the present lighting system analysis , faults in the system are identified only after the construction of design. This can lead to problems like excess illumination, glare, increased number of luminaires which in turn affect the energy efficiency of building. . In this method it is able to see that the problems of improper lighting can be solved before the construction. The user is able to get the effective lighting design before construction and it is able to change the lights and experience the same. The major part is the drawing using $3 \mathrm{ds}$ max software where the perspective view is formed actually. The moving and controlling of the lights is done in UNITY software.

Implementation of lighting design using virtual reality is a mobile application which helps to provide a platform with social VR experience [5].Along with this it enable the pre visualization of design before the construction. Therefore this concept pave an innovative approach in electrical system deign. Proper lighting in building and pre 
visualization of design improve overall interior performance and ensure energy saving. The whole system is very flexible and user friendly. So further changes to these systems, which are adding the needed features and the android application can be incorporated into easily and quickly. Adequate documentation provides for maintenance and enhancement. The final outcome is that with the help of a simple plan the virtual realization of the lighting design can be experienced by the user.

\section{REFERANCES}

[1]. T.H Rocky, Islam, U.K Saha, "A solution for rural market power crisis", $2^{\text {nd }} \quad$ international conference on green energy and technology, Dhaka, Bangladesh, sep 5,2014,pp. 14-17.

[2]. A. Sędziwy, "A new approach to street lighting design", Leukos, Vol.12, issue 3, Jul 2,2016, pp. 151162.

[3]. Zhongchao, Zhao, and Yang Weiju. "Calculation Accuracy Verification of Simulation software dialux for building lights" Architecture and culture vol.10,2013;

[4]. J.K. Stefanucci, S.P. O'Hargan, D.R. Proffitt, Augmenting contextdependent memory,Journal of Cognitive Engineering and Decision Making, 1 (4), 391-404, 2007.

[5]. S. N. B. Gunkel, H. M. Stokking, M. J. Prins, O. A. Niamut, E. Siahaan, and P. S. Cesar Garcia. Experiencing Virtual Reality Together: Social VR Use Case Study. In Proceedings of the 2018 .

[6]. J. W. Woodworth, S. Ekong, and C. W. Borst, C.W. Virtual field trips with networked depth-camera-based teacher, heterogeneous displays, and example energy center application. In 2017 IEEE Virtual Reality (VR), pages 471-472. IEEE, 2017.

[7]. M. J. Prins, S. N. B. Gunkel, H. M. Stokking, and O. A. Niamut. Together VR: A Framework for photorealistic shared media experiences in 360-degree VR. SMPTE Motion Imaging Journal 127.7:39-44, August 2018. 